\title{
Article \\ The Strategy of Active Grid Frequency Support for Virtual Synchronous Generator
}

\author{
Lingfang Yang ${ }^{1}$, Junpeng Ma ${ }^{1, *}$, Shunliang Wang ${ }^{1}$, Tianqi Liu ${ }^{1}$, Zihao Wu ${ }^{2}$, Ruogu Wang ${ }^{2}$ and Lutian Tang ${ }^{2}$ \\ 1 Department of Electrical Engineering, Sichuan University, Chengdu 610065, China; \\ yanglingfang@stu.scu.edu.cn (L.Y.); slwang@scu.edu.cn (S.W.); tqliu@scu.edu.cn (T.L.) \\ 2 Electric Power Research Institute of State Grid Shaanxi Electric Power Corporation, Xi'an 710054, China; \\ woozihao@gmail.com (Z.W.); xiopaul@sohu.com (R.W.); ttangecho@sohu.com (L.T.) \\ * Correspondence: jma@scu.edu.cn; Tel.: +86-151-0848-5887
}

check for updates

Citation: Yang, L.; Ma, J.; Wang, S.; Liu, T.; Wu, Z.; Wang, R.; Tang, L. The Strategy of Active Grid Frequency Support for Virtual Synchronous Generator. Electronics 2021, 10, 1131. https://doi.org/10.3390/electronics 10101131

Academic Editor: Nicu Bizon

Received: 12 April 2021

Accepted: 6 May 2021

Published: 11 May 2021

Publisher's Note: MDPI stays neutral with regard to jurisdictional claims in published maps and institutional affiliations.

Copyright: (c) 2021 by the authors. Licensee MDPI, Basel, Switzerland. This article is an open access article distributed under the terms and conditions of the Creative Commons Attribution (CC BY) license (https:// creativecommons.org/licenses/by/ $4.0 /)$.

\begin{abstract}
Virtual synchronous generator (VSG) control is a promising control approach for voltage source converters as an interface between new energy sources and the power grid. VSG is a gridfriendly control scheme, which can imitate the mechanical inertia of the synchronous generator (SG) and the power droop characteristics. Yet, the droop characteristics imitation of SG induces the frequency variation of the grid-connected inverter along with the droop characteristic curve, which will deteriorate the performance of the grid frequency support during the transient process. In this paper, a control scheme, which shapes the droop curve during the disturbance, is proposed for active grid frequency support. First, a load disturbance extraction strategy with a high-pass filter is applied in the proposed method, and the disturbance component is effectively extracted to compensate for the frequency reference variation in traditional VSG control. The grid frequency is actively supported by shaping the droop curve of active power to the frequency of VSG during the disturbance. Afterward, $H_{\infty}$ and $H_{2}$ norms are used as the objective function to quantify the control performance of the proposed method, and the particle swarm optimization (PSO) algorithm is applied to optimize the control parameters of the proposed method. With a well-optimized high-pass filter, the active support performance is further improved. Finally, the simulation results and hardware in the loop (HIL) tests verify the effectiveness of the proposed method.
\end{abstract}

Keywords: virtual synchronous generator; synchronous generator; high-pass filter; active frequency support; inertia

\section{Introduction}

The grid-connected inverter has been widely applied in the power grid with the increase of the penetration rate of renewable energy. The grid-friendly control scheme is mainly concerned for improving the interaction performance between the grid and the inverter. Traditionally, the control schemes for grid-connected inverter include gridfollowing control and grid-forming control [1]. The former, which includes constant current control, constant power control $[2,3]$, cannot support the power grid during the transient process. Therefore, a large number of inverters with grid-following control connected to the grid will reduce the system inertia, increase the frequency fluctuations, which is a serious challenge for the safe and stable operation of the power system [4-9].

To mitigate the negative effect caused by the inverters on the power grid, smart inverters (SIs) are designed and have been applied in several locations. SIs are inverters with advanced functions, which can improve the disturbance rejection ability and support the frequency and voltage of the power grid during the load disturbance $[10,11]$. However, the increase of total inertia is limited with SIs [12]. To solve the low inertia issue and overcome the frequency fluctuation more reliably, as the representative grid-forming control, the virtual synchronous generator (VSG) control has been widely studied in recent years [13-16]. VSG has similar natures to the synchronous generator, and it can simulate 
the mechanical inertia and the power droop characteristics. Therefore, VSG is an attractive control scheme for power grid support in the renewable energy system.

By the simulation for the inertia of the synchronous generator, the VSG control strategy enables the grid-connected inverter to participate extensively in the frequency regulation of the system [17]. In recent years, to fully utilize the benefits of VSG, various improvement strategy for VSG have been developed. By adding virtual inertia to the traditional droop control in [18], the transient response of the microgrid is improved. A novel control scheme for VSG, which damps the power and frequency oscillation, is introduced in [19]. For better analyzing the nature of VSG, the small-signal modeling and parameters design of the VSG are discussed in [20]. It can be concluded that the method of increasing virtual inertia results in a reduction of frequency overshoot in [21], however, bigger inertia induces slower dynamics. Comparing to the fixed inertia of the synchronous generator, the flexible and adjustable virtual inertia of VSG is more advantageous. For instance, a bang-bang rotational inertia adaptive control is proposed in [22]. By judging the frequency deviation and the slope of the frequency of VSG, two virtual inertia values are selected. However, the inertia in the bang-bang control jumps between the maximum value and the minimum value, and the control system thereby is sensitive to disturbances. To obtain more appropriate inertia, an adaptive virtual inertia strategy has been proposed in [23-25], which can realize the smooth transition of virtual inertia in the transient process. However, both the structure and the parameters design are complicated. Besides, a control method, which uses the frequency deviation to compensate the power difference, is proposed in [26], with which the slope of grid frequency can be introduced to the active power control loop of VSG. As a result, the frequency drop depth is reduced, but the compensation speed of this frequency deviation control is relatively slow. Furthermore, the grid frequency is generally obtained by the phase-locked loop (PLL), and the improper tune of the PLL parameters would deteriorate system stability [27].

Although the above research has indicated that the introduction of virtual inertia can effectively suppress the frequency fluctuations caused by load disturbances, currently, the studies on VSG technology mostly focus on the simulation or improvement of virtual inertia. These methods don't make full use of the flexible and controllable characteristics of the grid-connected inverter [28], which limits the performance of VSG of improving frequency stability. Most importantly, the VSG algorithm simulates the inertia of the synchronous generator and the characteristics of $P-f$ droop control and $Q-V$ droop control at the same time. As a result, the frequency of VSG and SG will change along with the $P-f$ droop characteristic curve. Therefore, the ability of VSG to support the grid frequency is limited, and grid frequency support can't be realized actively. To overcome the above issues, this paper proposes an active grid frequency support strategy for VSG. In the proposed method, the load disturbance power is first extracted by the high-pass filter and superimposed into the VSG control system. The transient frequency characteristic of the VSG thereby is improved. Meanwhile, more active power is provided by VSG, which has great significance for the promotion of the new energy.

In this paper, the microgrid system with VSG-SG interaction is built. VSG technology is being attractive in the microgrid, and SG is one of the typical reliable energy sources in the microgrid. Therefore, the paralleled VSG-SG coupling system is a normal scenario in microgrids $[29,30]$. Some research has been made to explore the paralleled synchronous and virtual synchronous generators system, which mainly includes the pre-synchronization control method [31], transient power-sharing [32], and transient angle stability [33]. However, the frequency stability issue in such a scenario is rarely concerned. Therefore, for the VSG-SG coupling system, the improvement of the frequency dynamic of SG is focused in this paper. The contributions of this paper are as follows:

1. In the VSG-SG coupling system, the closed-loop transfer function between the load disturbance input and the SG angular frequency output is built. The frequency dynamic of the VSG-SG coupling system is revealed by this closed-loop transfer function. 
2. An active grid frequency support strategy is proposed, which enables VSG to compensate for the power balance and effectively realize the active support of the grid frequency by a high-pass filter.

3. To further improve the frequency support performance of the power grid, the particle swarm optimization (PSO) algorithm is used to optimize the parameters of the proposed strategy.

The paper is organized as follows. The basic operation principle and frequency characteristics of the VSG-SG coupling system are introduced in Section 2. In Section 3, the active grid frequency support strategy is presented, the theory of PSO algorithm and $H_{\infty}$ and $\mathrm{H}_{2}$ norms are also elaborated. Then, simulation and hardware in the loop (HIL) test results are given in Section 4. The main conclusions are summarized in Section 5.

\section{Frequency Characteristics of VSG-SG Coupling System}

The simplified block diagram of the VSG-SG coupling system is shown in Figure 1, where three-phase voltage-source inverter and synchronous generator are connected to the load at the common coupling point (PCC). $U_{d c}$ represents the VSG's DC voltage. $u_{o a b c}$ and $i_{\text {oabc }}$ are the output voltage and current of the inverter, respectively. $L_{f}$ and $C_{f}$ are the filter inductor and capacitor, respectively. $L_{1}$ and $L_{2}$ are the line inductance of VSG and SG, respectively. $x_{t 1}$ and $x_{t 2}$ are the leakage reactance of SG export step-up transformer and step-down transformer, respectively.

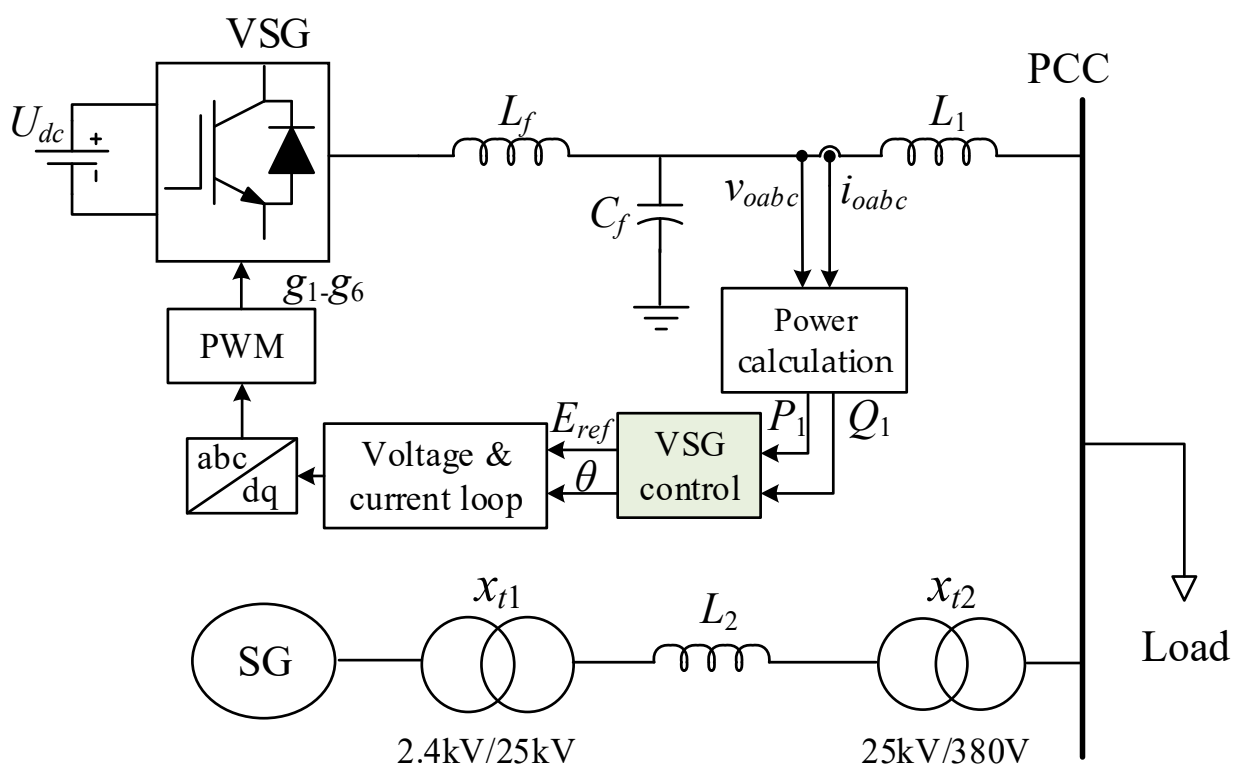

Figure 1. Main circuit and control diagram of VSG-SG coupling system.

\subsection{Control and Mathematical Model of VSG}

Figure 2 shows the block diagram of the VSG control, where $E_{r e f}$ and $\theta$ are the amplitude and the phase angle of the voltage reference, respectively. $E_{n}$ represents the rated voltage. $Q_{\text {set }}$ and $Q_{1}$ are the reactive power reference and output reactive power, respectively. $k_{\mathrm{q} 1}$ represents the voltage-drooping coefficient. The reactive power control emulates the excitation regulator, while the active power control emulates the rotor motion equation and the governor of the synchronous generator. 


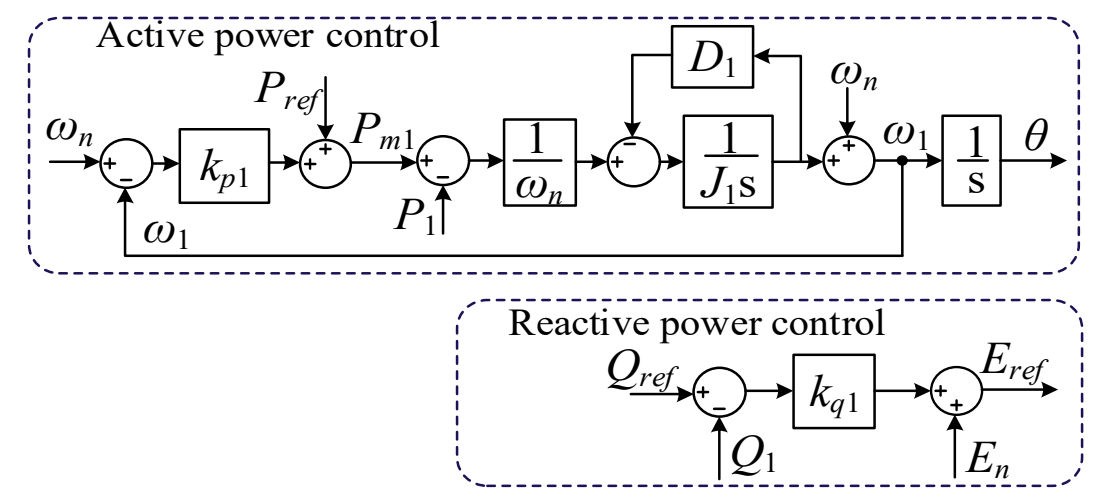

Figure 2. The VSG control diagram with active power and reactive power controller.

According to Figure 2, the rotor motion equation can be expressed as

$$
J_{1} \frac{d \omega_{1}}{d t}=\frac{P_{m 1}}{\omega_{n}}-\frac{P_{1}}{\omega_{n}}-D_{1}\left(\omega_{1}-\omega_{n}\right)
$$

where $\omega_{n}$ represents the rated angular frequency. $\omega_{1}$ is the virtual angular frequency of VSG. $P_{m 1}$ and $P_{1}$ are the virtual mechanical active power and output active power, respectively. $J_{1}$ represents the virtual inertia, and $D_{1}$ is the damping coefficient.

The virtual governor reflects the primary frequency characteristics of the synchronous generator, which can be represented as

$$
P_{m 1}=P_{r e f}+k_{p 1}\left(\omega_{n}-\omega_{1}\right)
$$

where $P_{\text {ref }}$ is the active power reference. $k_{p 1}$ is the droop coefficient.

Substituting Equation (2) into Equation (1), and Equation (3) can be derived by the small-signal linearization method.

$$
\Delta \omega_{1}=-\frac{1}{J_{1} \omega_{n} s+D_{1} \omega_{n}+k_{p 1}} \Delta P_{1}
$$

\subsection{Control and Mathematical Model of SG}

The control system of the synchronous generator consists of an excitation regulator and governor. Figure 3 shows the governor control block diagram.

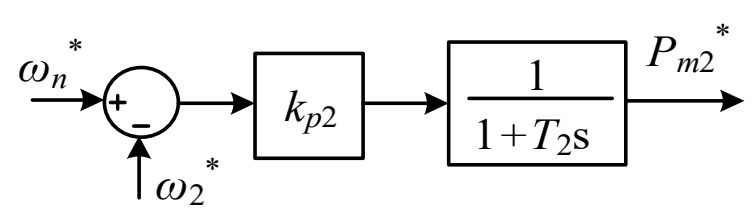

Figure 3. The governor diagram of synchronous generator.

According to Figure 3, the mechanical active power $P_{m 2}{ }^{*}$ of SG satisfies

$$
P_{m 2}^{*}=\frac{k_{p 2}}{1+T_{2} s}\left(\omega_{n}^{*}-\omega_{2}^{*}\right)
$$

where $\omega_{2}{ }^{*}$ represents the angular frequency of SG. $k_{p 2}$ and $T_{2}$ represent the proportional coefficient and time-delay constant of the governor, respectively. Superscript "** indicates the nominal value.

The rotor motion equation of SG can be expressed as

$$
T_{j} \frac{d \omega_{2}^{*}}{d t}=P_{m 2}^{*}-P_{2}^{*}
$$


where $T_{j}$ is the inertial constant.

Combining with Equations (4) and (5), the relation between $\Delta \omega_{2}$ and $\Delta P_{2}$ can be written as Equation (6) by the small-signal linearization method.

$$
\Delta \omega_{2}=-\frac{\omega_{n}}{S_{\text {base }}} \frac{1+T_{2} s}{T_{j} T_{2} s^{2}+T_{j} s+k_{p 2}} \Delta P_{2}
$$

where $S_{\text {base }}$ is the power reference value.

\subsection{Model of VSG-SG Coupling System}

The VSG and SG are equivalent to the ideal voltage source with an output impedance, as shown in Figure $4, E_{1}$ and $E_{2}$ are the root mean square values of VSG and SG output voltages, respectively. $\theta_{1}$ and $\theta_{2}$ are the output voltage phase of VSG and SG, respectively. $V_{p c c}$ and $\theta_{p c c}$ represent the root mean square value and phase of the PCC voltage, respectively. $X_{1}$ and $X_{2}$ represent the equivalent reactance of VSG and SG, respectively. $P_{\text {load }}$ is the load active power.

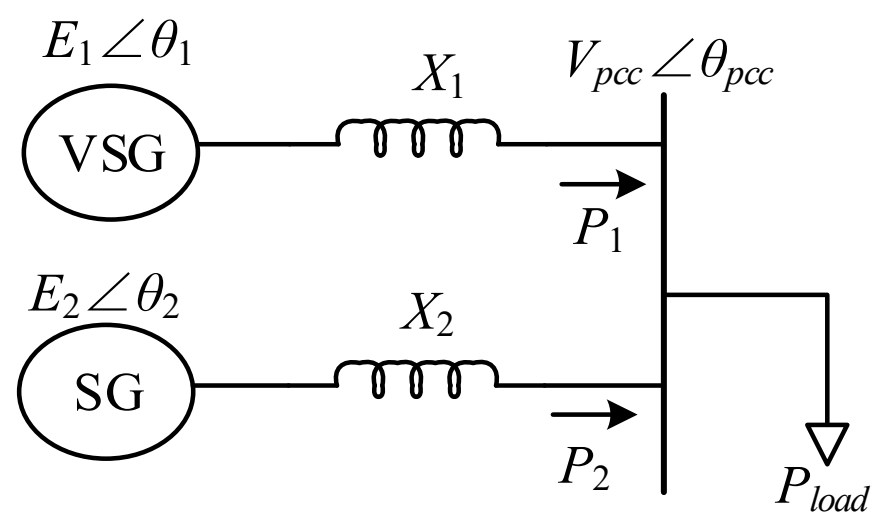

Figure 4. Equivalent circuit of VSG-SG coupling system.

According to Figure 4, the expressions of output active power of VSG and SG can be written as

$$
\left\{\begin{array}{l}
P_{1}=\frac{3 E_{1} V_{p c c}}{X_{1}} \sin \left(\theta_{1}-\theta_{p c c}\right)=\frac{3 E_{1} V_{p c c}}{X_{1}} \sin \delta_{1} \\
P_{2}=\frac{3 E_{2} V_{p c c}}{X_{2}} \sin \left(\theta_{2}-\theta_{p c c}\right)=\frac{3 E_{2} V_{p c c}}{X_{2}} \sin \delta_{2}
\end{array}\right.
$$

where $\delta_{1}$ and $\delta_{2}$ are the phase angle difference of VSG and SG output voltage relative to PCC voltage, respectively. The relation between the phase angles can be expressed as

$$
\left\{\begin{array}{l}
\frac{d\left(\theta_{1}-\theta_{p c c}\right)}{d t}=\frac{d \delta_{1}}{d t}=\omega_{1}-\omega_{p c c} \\
\frac{d\left(\theta_{2}-\theta_{p c c}\right)}{d t}=\frac{d \delta_{2}}{d t}=\omega_{2}-\omega_{p c c}
\end{array}\right.
$$

The Equation (9) can be derived by linearizing Equation (7) and (8).

$$
\begin{gathered}
\left\{\begin{array}{l}
\Delta P_{1}=\frac{3 E_{1} V_{p c c}}{X_{1}} \cos \delta_{1} \Delta \delta_{1}=K_{1} \Delta \delta_{1} \\
s \Delta \delta_{1}=\Delta \omega_{1}-\Delta \omega_{p c c}
\end{array}\right. \\
\left\{\begin{array}{l}
\Delta P_{2}=\frac{3 E_{2} V_{p c c}}{X_{2}} \cos \delta_{2} \Delta \delta_{2}=K_{2} \Delta \delta_{2} \\
s \Delta \delta_{2}=\Delta \omega_{2}-\Delta \omega_{p c c}
\end{array}\right.
\end{gathered}
$$

Based on the power conservation relationship, the load disturbance power can be written as

$$
\Delta P_{1}+\Delta P_{2}=\Delta P_{\text {load }}
$$


Substituting Equation (6) into (10), the angular frequency of PCC can be expressed as

$$
\Delta \omega_{p c c}=\frac{\left(T_{2} s+1\right) \omega_{n}}{S_{b a s e}\left(T_{2} T_{j} s^{2}+T_{j} s+k_{p 2}\right)} \Delta P_{2}-\frac{s}{K_{2}} \Delta P_{2}
$$

Substituting Equations (12) and (13) into (9), The relation between active power $\Delta P_{1}$ and $\Delta P_{2}$ can be expressed as

$$
\Delta P_{1}=\frac{K_{1}(1+A)}{K_{2}(1+B)} \Delta P_{2}
$$

where

$$
\left\{\begin{array}{c}
A=\frac{K_{2} \omega_{n}\left(T_{2} s+1\right)}{S_{\text {base }}\left(T_{2} T_{j} s^{3}+T_{j} s^{2}+k_{p 2}\right)} \\
B=\frac{K_{1}}{J_{1} \omega_{n} s^{2}+\left(k_{p 1}+D_{1} \omega_{n}\right) s}
\end{array}\right.
$$

In VSG and SG coupling system, we focus on the SG frequency rather than the VSG frequency because the former is considered as the main reliable energy source.

Combining with Equations (6), (11) and (13), the closed-loop transfer function between the load disturbance input and the SG frequency output can be obtained.

$$
G^{\prime}(s)=\frac{\Delta \omega_{2}}{\Delta P_{\text {load }}}=\frac{b_{3}^{\prime} s^{3}+b_{2}^{\prime} s^{2}+b_{1}^{\prime} s+b_{0}^{\prime}}{a_{4}^{\prime} s^{4}+a_{3}^{\prime} s^{3}+a_{2}^{\prime} s^{2}+a_{1}^{\prime} s+a_{0}^{\prime}}
$$

where the coefficients $a_{0}{ }^{\prime}-a_{4}{ }^{\prime}, b_{0}{ }^{\prime}-b_{3}{ }^{\prime}$ are presented in Appendix A.

\section{Active Grid Frequency Support Strategy}

3.1. Frequency Characteristics of VSG-SG Coupling System Based on Active Grid Frequency Support Strategy

This paper proposes a load power extraction strategy based on the first-order highpass filter to provide active frequency support. The structure of the proposed control strategy is shown in Figure 5. Under the proposed control scheme, the load disturbance component is introduced into the active power control of the virtual synchronous generator without detecting other variables. Simultaneously, the control structure is relatively simple, and the VSG can detect the change of active power directly under load disturbance. In other words, the proposed control strategy can actively provide additional power to improve the frequency stability of the synchronous generator.

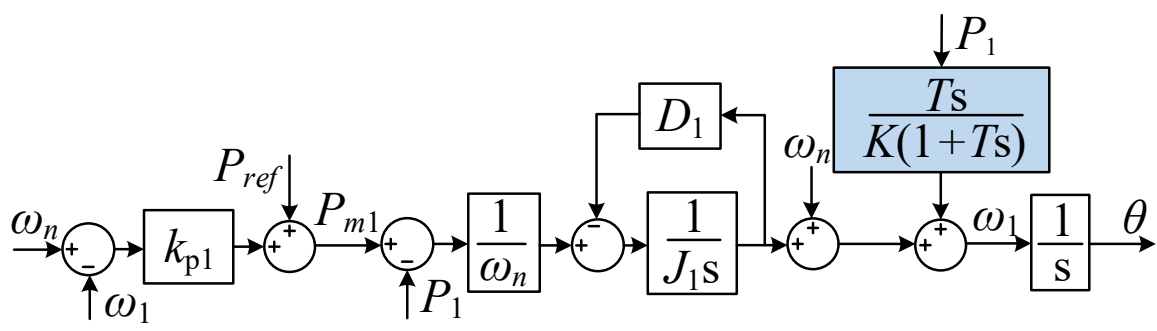

Figure 5. Active power control block diagram of VSG based on the first-order high-pass filter.

According to Figure 5, the active loop control equation of the VSG after introducing the high-pass filter can be written as

$$
\omega_{1}=\omega_{n}+\frac{P_{r e f}+k_{p 1}\left(\omega_{n}-\omega_{1}\right)-P_{1}}{J_{1} \omega_{n} s+D_{1} \omega_{n}}+\frac{T s}{K(1+T s)} P_{1}
$$

where $K$ and $T$ are the proportional coefficient and time constant of the high-pass filter, respectively. 
Combining with Equations (6), (9), (10) and (16), the closed-loop transfer function between load disturbance input and SG frequency output can be obtained as

$$
G(s)=\frac{\Delta \omega_{2}}{\Delta P_{\text {load }}}=\frac{b_{4} s^{4}+b_{3} s^{3}+b_{2} s^{2}+b_{1} s+b_{0}}{a_{5} s^{5}+a_{4} s^{4}+a_{3} s^{3}+a_{2} s^{2}+a_{1} s+a_{0}}
$$

where the coefficients $a_{0}-a_{5}, b_{0}-b_{5}$ are presented in Appendix A.

Figure 6 shows the frequency output characteristics of the traditional $P-f$ droop control and the active frequency support strategy proposed in this paper. As the load increases, the operating points of the VSG in the two modes move from point A to point $B$ along the blue and red curves, respectively. It can be observed that the active frequency support strategy changes the VSG frequency output characteristic during the transient process, and then provides active support for the grid frequency.

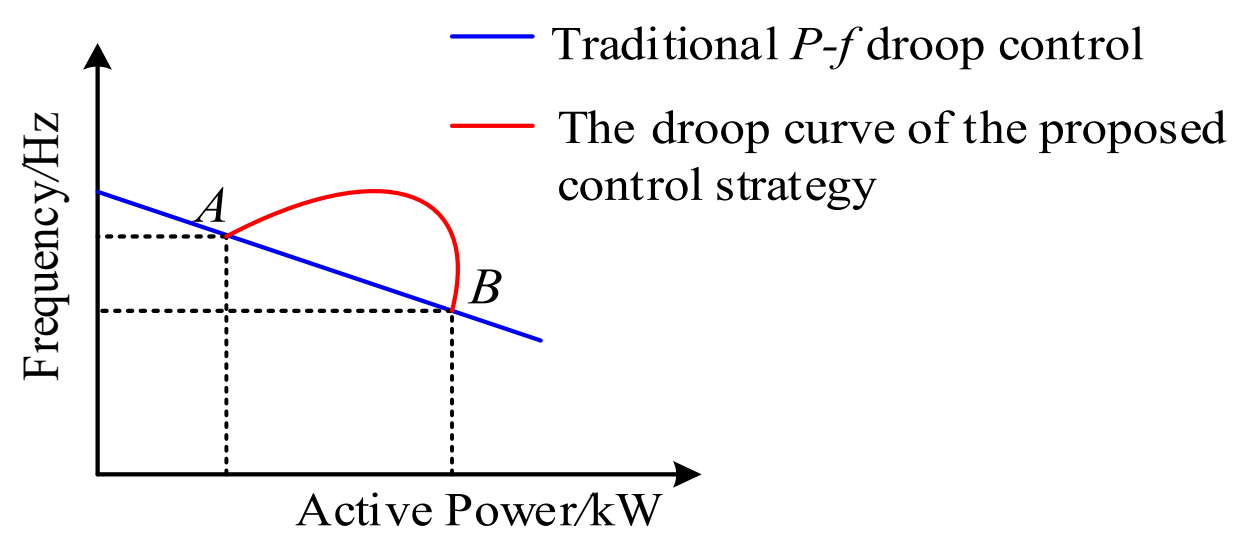

Figure 6. Comparison of frequency characteristics in transient process between traditional droop control and the proposed control method.

\subsection{Optimization of High-Pass Filter Parameters}

By taking the first-order high-pass filter into the active power control of VSG, the active power support for the system can be provided. Meanwhile, the frequency fluctuation can be reduced after a load disturbance. However, the control performance is related to the parameters $K$ and $T$ of the high-pass filter, where the duration of power support depends on the time constant of the high-pass filter. The value of power support depends on the proportional coefficient. Therefore, the optimization design of parameters $K$ and $T$ is necessary to further improve the frequency support performance.

\subsection{1. $\mathrm{H}_{\infty}$ and $\mathrm{H}_{2}$ Norms}

To analyze the effect of the high-pass filter on the disturbance suppression ability of the SG frequency quantitatively, the $H_{\infty}$ and $H_{2}$ norms of the transfer function $G(s)$ shown in the Equation (17) can be utilized as a performance indicator. The $H_{\infty}$ norm represents the maximum gain of the closed-loop system in the frequency domain. It indicates the disturbance suppression ability at the resonance frequency, which is more related to the damping characteristics. The $\mathrm{H}_{2}$ norm reflects the system's control performance in the entire frequency band, which is related to the overshoot [34]. The smaller $H_{\infty}$ and $H_{2}$ norms, the stronger the disturbance rejection ability of the system. In other words, the disturbance suppression ability is improved with the decrease of $H_{\infty}$ and $H_{2}$ norms.

The $H_{\infty}$ and $H_{2}$ norms of the transfer function $G(s)$ are defined as [35]

$$
\begin{aligned}
\|G(s)\|_{\infty} & =\sup _{\omega} \bar{\sigma}[G(j \omega)] \\
\|G(s)\|_{2} & =\sqrt{\frac{1}{2 \pi} \int_{-\infty}^{\infty} \operatorname{trace}\left[G(j \omega)^{H} G(j \omega)\right] d \omega}
\end{aligned}
$$


where $\bar{\sigma}[G(j \omega)]$ represents the largest singular value of $G(j \omega) . G^{H}$ is the conjugate transpose of $G$ and $\operatorname{trace}(G)$ represents the trace of $G$.

\subsubsection{Particle Swarm Optimization Algorithm}

Although the $H_{\infty}$ and $H_{2}$ norms can effectively reflect the impact of disturbance input on output, the analytic expression of the Equation (18) is extremely complicated. After substituting the transfer function $G(s)$ into the Equation (18), the analytic expression of the optimal solution of parameters $K$ and $T$ cannot be obtained directly. Thus, optimal algorithmic techniques need to be carried out to search optimal parameters $K$ and $T$, such as butterfly algorithmic (BOA) [36], genetic algorithm (GA) [37]. The particle swarm optimization algorithm (PSO) is considered in this paper due to its higher convergence characteristic with lesser elapsed time [38].

The PSO algorithm is a random optimization algorithm based on swarm intelligence [39]. The position in the search space represents a potential solution to the optimization problem. Each particle's characteristic can be represented by indicators, such as the particle's position, velocity, and fitness value, where the fitness value determines the quality of the particle. Particles are updated by following two factors: one is the individual's best position ever found $\left(P_{i d}\right)$; the other is the group's best position $\left(P_{g d}\right)$. In every iteration, the particle updates its position and velocity with Equation (19).

$$
\begin{aligned}
& V_{i d}^{k+1}=w V_{i d}^{k}+c_{1} r_{1}\left(P_{i d}^{k}-X_{i d}^{k}\right)+c_{2} r_{2}\left(P_{g d}^{k}-X_{i d}^{k}\right) \\
& X_{i d}^{k+1}=X_{i d}^{k}+V_{i d}^{k+1}
\end{aligned}
$$

where $w$ is the inertia weight. $k$ represents the iteration number. $c_{1}$ and $c_{2}$ are learning factors, respectively. $r_{1}$ and $r_{2}$ are random numbers between 0 and $1 . V_{i d}$ and $X_{i d}$ are the velocity and position of $i$-th particle, respectively.

To improve the search performance of the PSO algorithm, a method of dynamic inertia weight is considered, and the dynamic inertia weight coefficient can be given as

$$
w(k)=w_{\text {start }}-\left(w_{\text {start }}-w_{\text {end }}\right)\left(\frac{k}{T_{\max }}\right)^{2}
$$

where $T_{\max }$ represents the maximum number of iterations. Generally, the algorithm performance is the best when $w_{\text {start }}$ is 0.9 and $w_{\text {end }}$ is 0.4 [40].

The $H_{\infty}$ and $H_{2}$ norms are utilized as an index to describe the frequency response characteristics of the system, which can reflect the system's performance to suppress disturbances. Therefore, this paper chooses the weight of $H_{\infty}$ and $H_{2}$ norms as the objective function

$$
\min J=\alpha\|G(s)\|_{\infty}+(1-\alpha)\|G(s)\|_{2}
$$

where $G(s)$ represents the transfer function shown in the Equation (17). $\alpha$ is the weight coefficient in the range $[0,1]$, which represents the proportion of the $H_{\infty}$ norm in the objective function.

Figure 7 shows the three-dimensional graph, which reflects the relation between objective function $J$ and parameters $K$ and $T$ of the high-pass filter under different weight coefficients. It can be observed that the objective function in Figure $7 \mathrm{a}, \mathrm{b}$ has a minimum value, and the optimal results under different weight coefficients are different; whereas, the optimal results with different weight coefficients are not comparable since the weight coefficients are selected according to design requirements. When $\alpha$ is set to be smaller than 0.5 , better performance of $H_{2}$ norm is obtained. When $\alpha$ is set to be larger than 0.5 , better performance of $H_{\infty}$ norm is obtained. In this paper, the value of $\alpha$ is chosen as 0.7. 


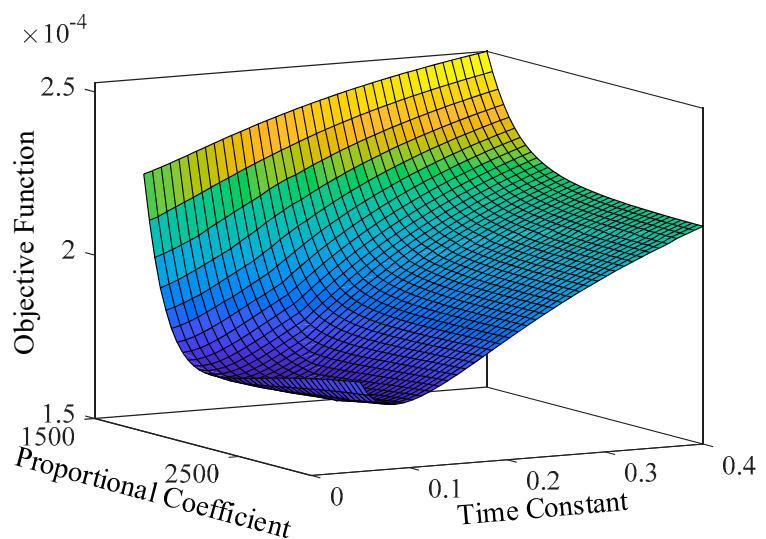

(a)

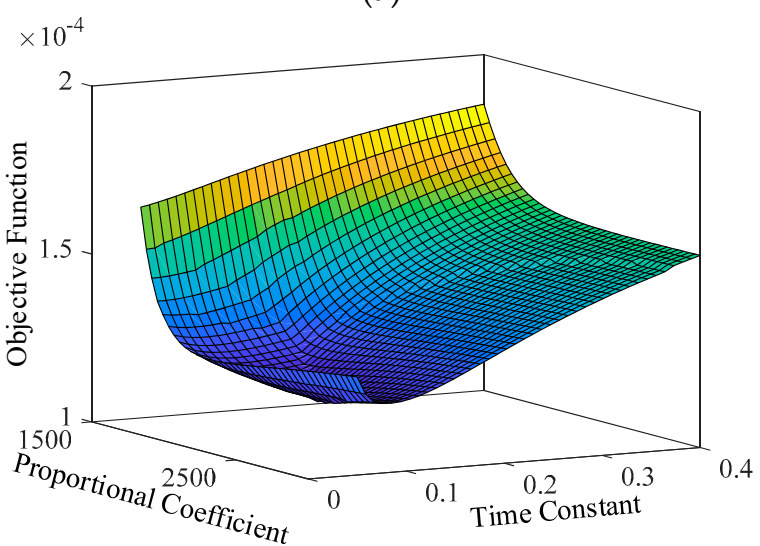

(b)

Figure 7. The relation between objective function $J$, proportional coefficient $K$, and time constant $T$ with: (a) $\alpha=0.3$; (b) $\alpha=0.7$.

\section{Verification of Proposed Strategy}

The effectiveness of the proposed active grid frequency support strategy is first verified by the simulation for a VSG-SG coupling system shown in Figure 1 in MATLAB/SIMULINK, and the system parameters are listed in Table 1 . The switching frequency is $10 \mathrm{kHz}$. At the initial operating point of the system, the load is a constant power load with $15 \mathrm{~kW}$. A $10 \%$ load disturbance is increased suddenly at $2 \mathrm{~s}$.

Table 1. Parameters of the VSG-SG coupling system.

\begin{tabular}{cccc}
\hline Parameters & Values & Parameters & Values \\
\hline$L_{f}$ & $2 \mathrm{mH}$ & $T_{j}$ & $2.4 \mathrm{~s}$ \\
$C_{f}$ & $20 \mu \mathrm{F}$ & $x_{t 1}$ & $0.03 \mathrm{p} . \mathrm{u}$. \\
$L_{1}$ & $10 \mathrm{mH}$ & $x_{t 2}$ & $0.03 \mathrm{p} . \mathrm{u}$. \\
$J_{1}$ & $0.06 \mathrm{~kg} \cdot \mathrm{m}^{2}$ & $L_{2}$ & $10 \mathrm{mH}$ \\
$D_{1}$ & $5 \mathrm{~N} \cdot \mathrm{m} \cdot \mathrm{s} / \mathrm{rad}$ & $k_{p 2}$ & 100 \\
$S_{\text {base }}$ & $50 \mathrm{kVA}$ & $T_{2}$ & 0.1 \\
$P_{\text {ref }}$ & $7 \mathrm{~kW}$ & $Q_{\text {ref }}$ & $0 \mathrm{Var}$ \\
$S_{S G}$ & $50 \mathrm{kVA}$ & $U_{d c}$ & $800 \mathrm{~V}$ \\
\hline
\end{tabular}

According to Equations (15) and (17), the frequency response of the SG during a load disturbance can be obtained. Additionally, the comparison between theoretical analysis and simulation results is shown in Figure 8. It can be seen in Figure 8 that theoretical results obtained by the small-signal model can accurately represent the dynamics of the system, which verifies the correctness of the small-signal model. 


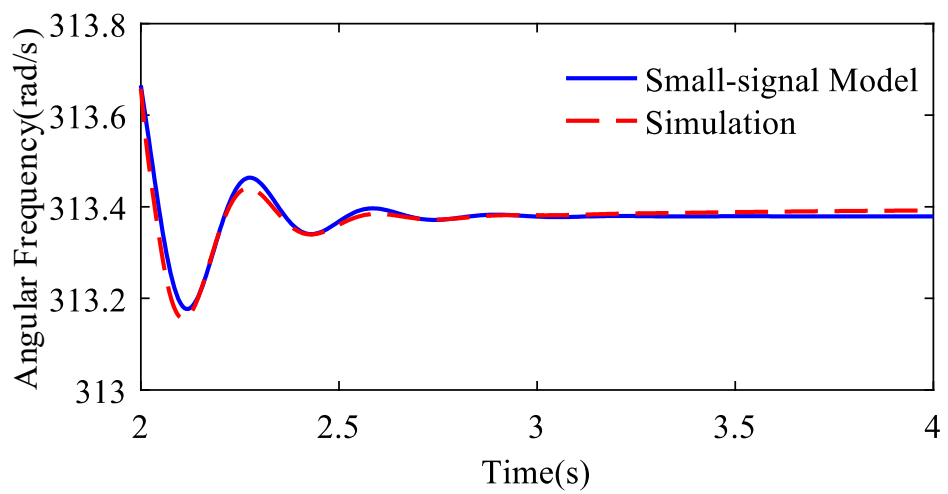

(a)

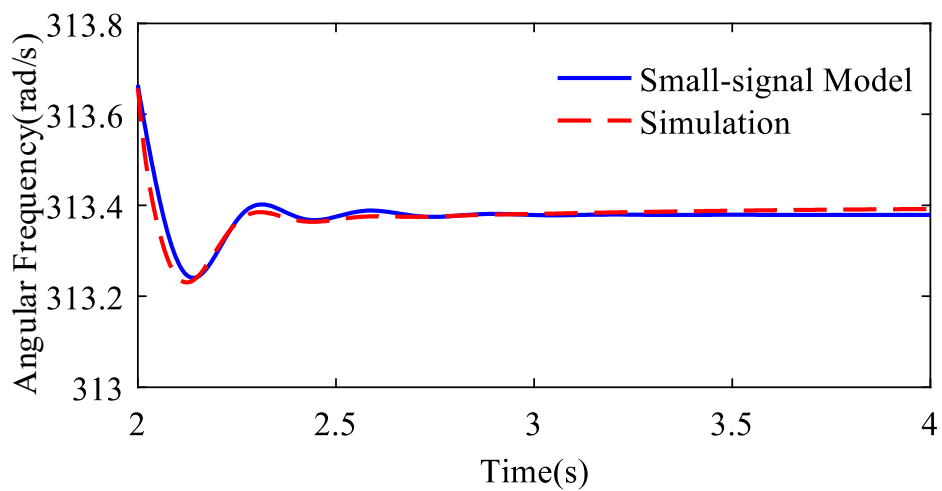

(b)

Figure 8. Step responses of SG angular frequency: (a) without the high-pass filter; (b) with the high-pass filter.

\subsection{Simulation Results with Constant Power Load}

The PSO parameters are chosen as $c_{1}=c_{2}=1.425$ and $T_{\max }=100$. The original parameters $K$ and $T$ of the high-pass filter are set as 2000 and 0.07 , respectively. The high-pass filter parameters can be optimized as $K=1658.2$ and $T=0.1$.

To verify the effectiveness of the strategy quantitatively, the $H_{\infty}$ and $H_{2}$ norms are calculated and presented in Table 2.

Table 2. Comparison of $H_{\infty}$ and $H_{2}$ norms in three cases.

\begin{tabular}{ccc}
\hline Cases & $\boldsymbol{H}_{\infty}$ Norm & $\boldsymbol{H}_{\mathbf{2}}$ Norm \\
\hline without the high-pass filter & $1.5457 \times 10^{-4}$ & $3.3907 \times 10^{-4}$ \\
with the high-pass filter & $1.0565 \times 10^{-4}$ & $2.6175 \times 10^{-4}$ \\
with the high-pass filter/parameters optimized & $8.8968 \times 10^{-5}$ & $2.1899 \times 10^{-4}$ \\
\hline
\end{tabular}

Table 2 shows that when the high-pass filter is added to the active power loop of the VSG, the $H_{\infty}$ and $H_{2}$ norms are reduced. Moreover, $H_{\infty}$ and $H_{2}$ norms with optimized parameters are further reduced, which indicates that the disturbance rejection ability of SG is gradually increasing, and the frequency fluctuation is decreasing.

Figure 9 shows the angular frequency of VSG under three cases. In case 1, a high-pass filter for load disturbance extraction is not used in VSG control, and in case 2, the high-pass filter is introduced in VSG control without optimized parameters. In the last case, the control parameters of the proposed method are optimized. 


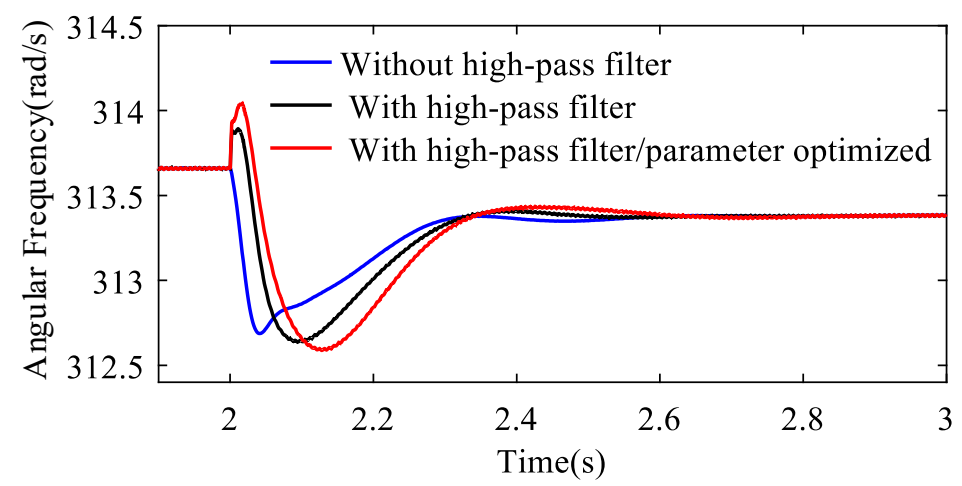

Figure 9. The simulation result of VSG angular frequency in three cases under the condition of load sudden increase.

In Figure 9, the frequency of the VSG without the high-pass filter directly drops due to the droop characteristic under the increase of load power. On the contrary, when adopting the VSG control strategy proposed in this paper, the frequency increases first during the transient process, which demonstrates that the VSG control strategy based on the high-pass filter is an active frequency support strategy.

Figure 10 and Figure 12 show the angular frequency of SG and PCC point under three cases, respectively. The active power comparison of SG and VSG is shown in Figure 11.

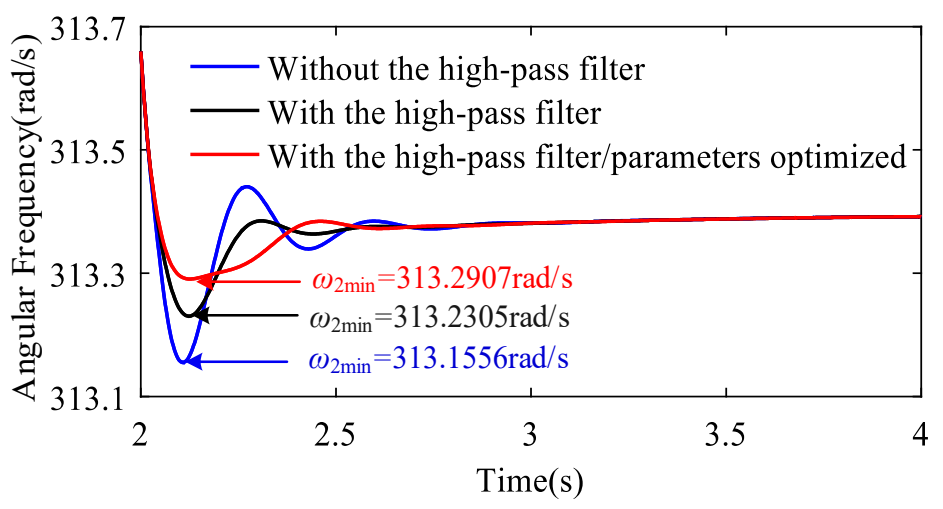

Figure 10. The simulation result of SG angular frequency in three cases under the condition of load sudden increase.

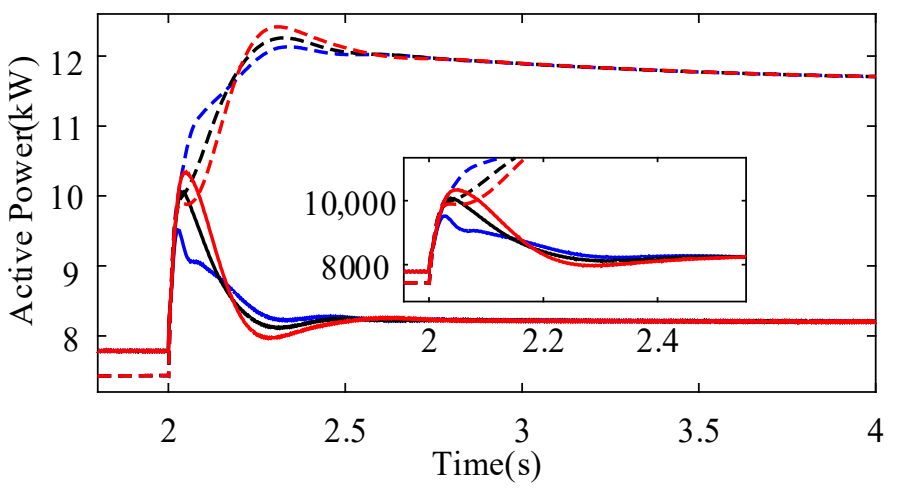

- $P_{v s g} /$ without the high-pass filter--- $P_{s g} /$ without the high-pass filter

$-P_{v s g} /$ with the high-pass filter $\quad--P_{s g} /$ with the high-pass filter

$-P_{v s g} /$ with the high-pass filter/parameters optimized

$---P_{s g} /$ with the high-pass filter/parameters optimized

Figure 11. The simulation result of active power in three cases under the condition of load sudden increase. 
From Figures 10 and 11, it can be seen that the conventional VSG control strategy without a high-pass filter shows the most serious oscillation. In comparison, with the proposed strategy, the VSG actively shares more active power during the load disturbance and extends the supporting time of the active power. The SG frequency nadir is increased from 313.1556 to $313.2305 \mathrm{rad} / \mathrm{s}$, and the slope of frequency is reduced. After adopting the high-pass filter with optimized parameters based on the PSO algorithm, the angular frequency performance of SG is the best compared with other cases. Furthermore, since the VSG provides more additional power and extends the duration of power support, the damping of the system becomes larger, which attenuates the frequency oscillations.

As shown in Figure 12, the frequency response of the PCC point in different cases also demonstrates that the proposed strategy has the ability of active frequency support.

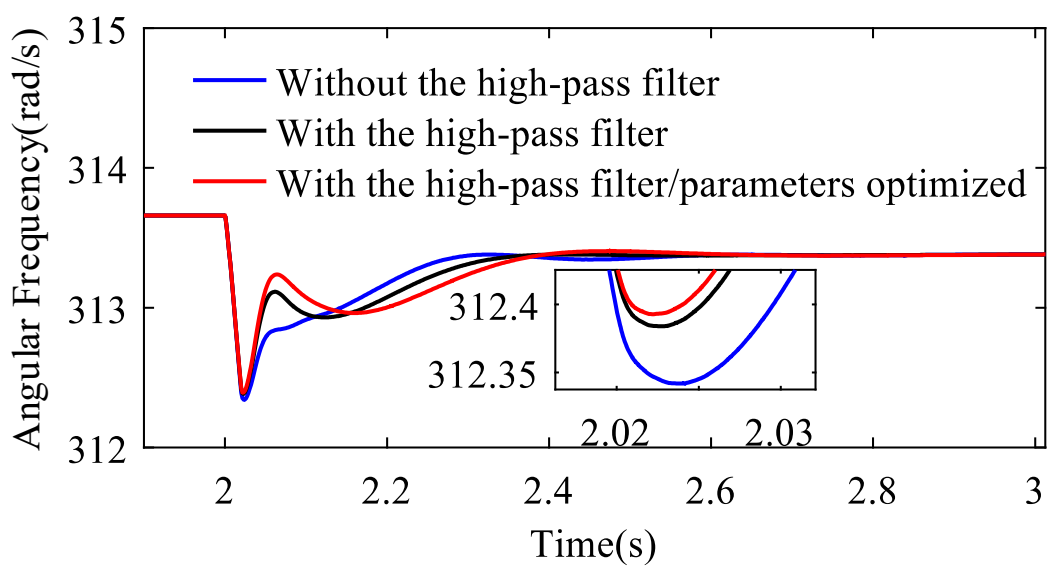

Figure 12. The simulation result of PCC angular frequency in three cases under the condition of load sudden increase.

\subsection{Simulations Results with Full Load}

Asynchronous motors are a common type of load in the actual power system. Therefore, to show the effectiveness of the proposed method with different load types, the asynchronous motor is considered here instead of constant power load. The simulation results in different cases, i.e., without the high-pass filter, with the high-pass filter, and with the parameters optimized high-pass filter, are displayed in Figures 13 and 14.

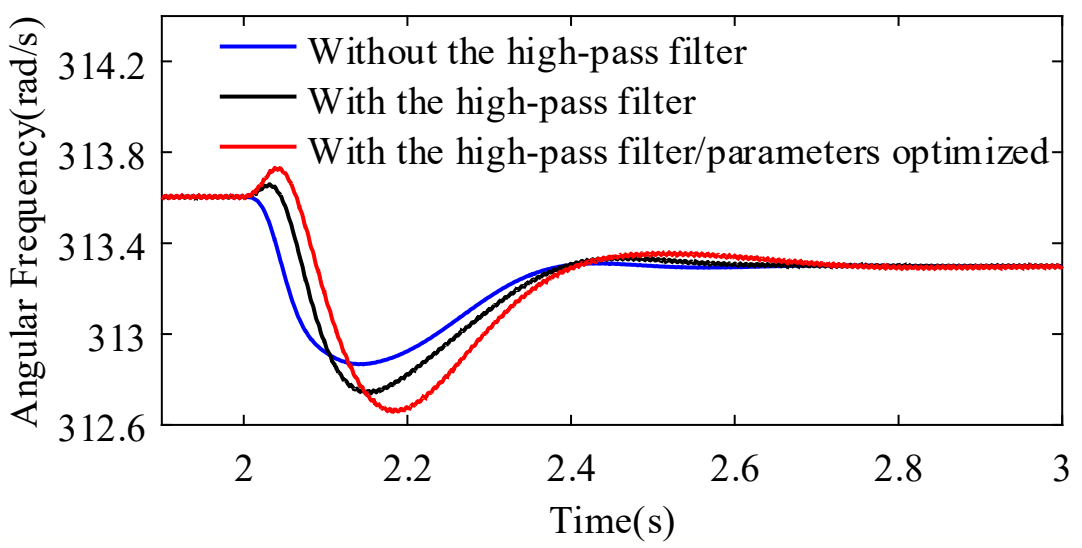

Figure 13. The simulation result of VSG angular frequency with the asynchronous motor load. 


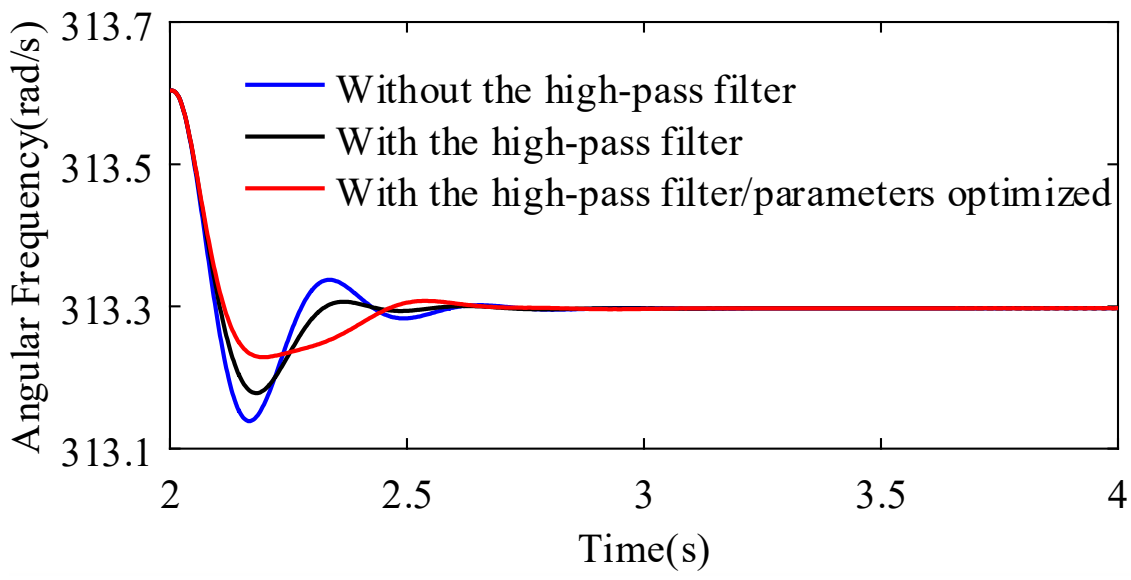

Figure 14. The simulation result of SG angular frequency with the asynchronous motor load.

Figure 13 shows the simulation result of VSG angular frequency in three cases. It can be seen in Figure 13 that the VSG angular frequency increases first during the transient process, while the frequency of conventional VSG control without the high-pass filter decreases directly due to the droop characteristic. Thus, it can be found that the VSG control strategy based on the high-pass filter is an active frequency support strategy.

The simulation result of SG angular frequency with the asynchronous motor load is shown in Figure 14. The frequency curves in the three cases depict that the proposed method with the optimized high-pass filter is superior to the other methods, and the proposed method has lower frequency deviation and smaller frequency oscillation. The simulation results show the effectiveness of the proposed control strategy and the PSO algorithm once again.

\subsection{Comparison with Other Control Method}

To show the superiority of the active grid frequency support strategy, the method of increasing virtual inertia $J$ in [21] and bang-bang-control in [22] are compared, and these two approaches are the typical frequency improvement scheme of VSG. The comparative performances of different methods are displayed in Figures 15 and 16, respectively.

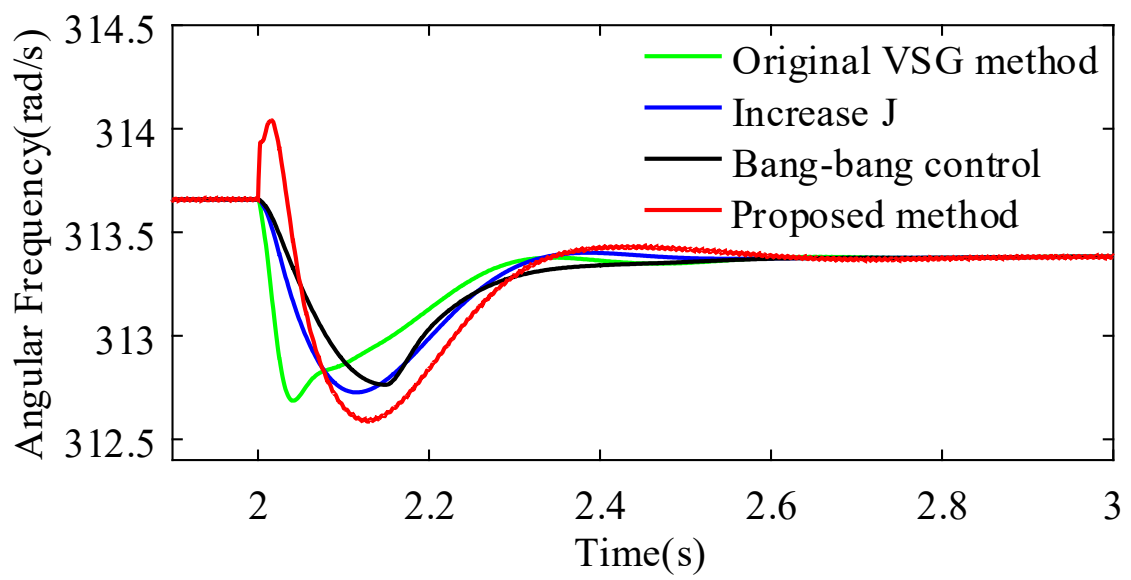

Figure 15. The simulation result of VSG angular frequency with three methods. 


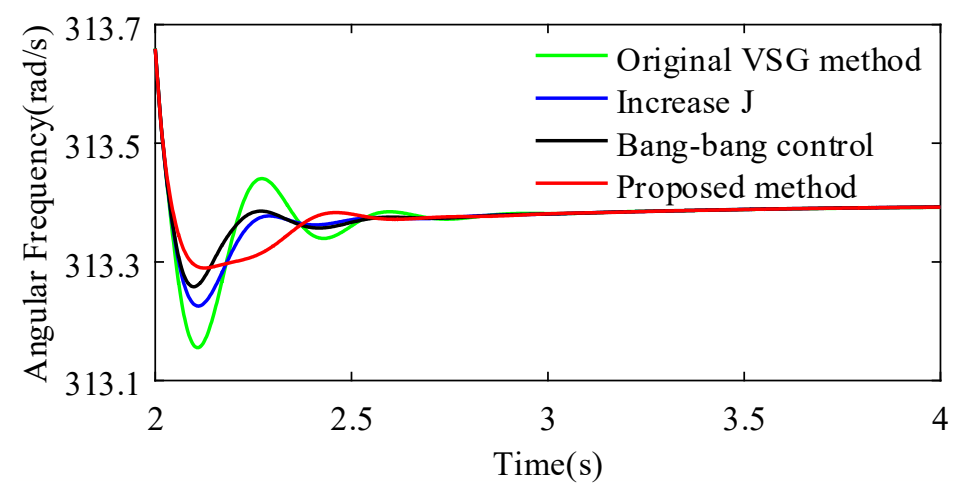

Figure 16. The simulation result of SG angular frequency with three methods.

According to the VSG angular frequency of Figure 15, it can be seen clearly that the VSG angular frequency increases first when the load increases, which is quite different from the other two methods. Therefore, it can be proved that the active support characteristics can only be implemented by the proposed method.

Figure 16 shows the comparison of SG angular frequency. It can be observed that these three methods can improve frequency response effectively. A better frequency performance can be obtained by bang-bang control compared with the method of increasing $J$. When the proposed approach, i.e., active frequency support strategy is employed, the enhancement effect on SG angular frequency is more obvious, and the simulation results show the superiority of the proposed method.

\subsection{Hardware in the Loop Experimental Test}

To further verify the active grid frequency support strategy, a HIL experimental platform is established, as shown in Figure 17. The experimental platform consists of HIL real-time simulator and rapid control prototyping (RCP), host computer, and oscilloscope. The HIL has CPU and FPGA resources for real-time calculations, which simulates the VSG-SG coupling system. Meanwhile, the VSG control strategy is implemented in RCP. Here the HIL simulator and RCP are connected to exchange voltage signals, current signals, and PWM signals through the physical IO interface. The experimental parameters are consistent with the simulation, and the disturbance is simulated by switching the load.

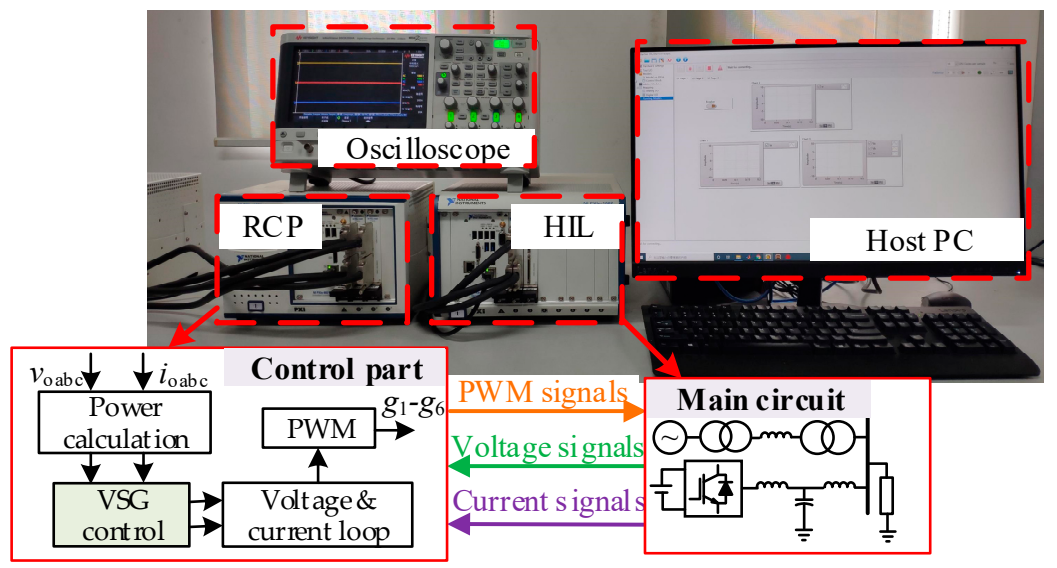

Figure 17. Photograph of the semi-physical experimental platform.

Figure 18 shows the waveform of the SG angular frequency. From Figure 18a,b, it can be observed that the system with conventional VSG control will endure a larger frequency deviation, where the overshoot is $0.5432 \mathrm{rad} / \mathrm{s}$. In the proposed method, the overshoot is reduced to $0.471 \mathrm{rad} / \mathrm{s}$. Compared with the original parameters of the high-pass filter, the frequency deviation, which is less than $25.9 \%$, has a significant improvement as Figure $18 \mathrm{c}$. 


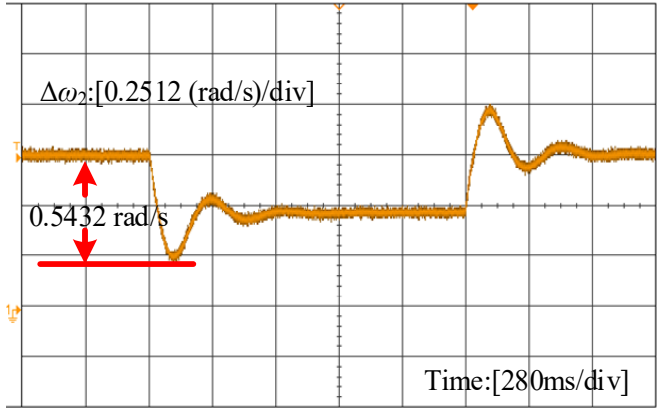

(a)

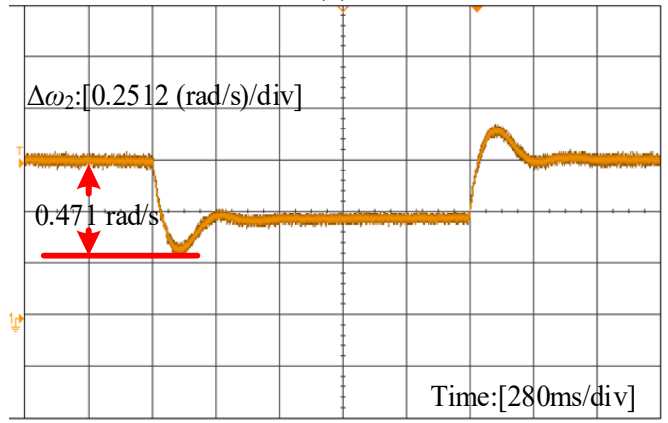

(b)

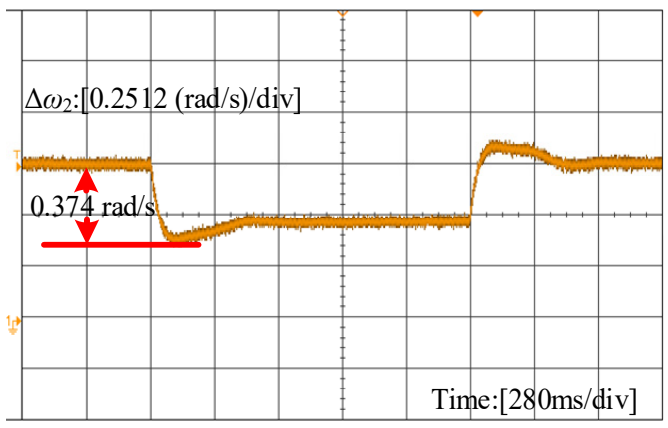

(c)

Figure 18. SG angular frequency waveform: (a) without the high-pass filter; (b) with the high-pass filter; (c) with the high-pass filter (parameters optimized).

Figure 19 shows the waveform of the output active power. As shown in Figure 19c, the proposed strategy with the optimized parameter can provide more active power support compared to the cases with and without the proposed control shown in Figure 19a,b, respectively. Thus, the frequency deviation and oscillation are significantly reduced. It is concluded that the active grid frequency support strategy can effectively improve the system frequency response characteristics. Meanwhile, these experimental results are in good accordance with the simulation results.

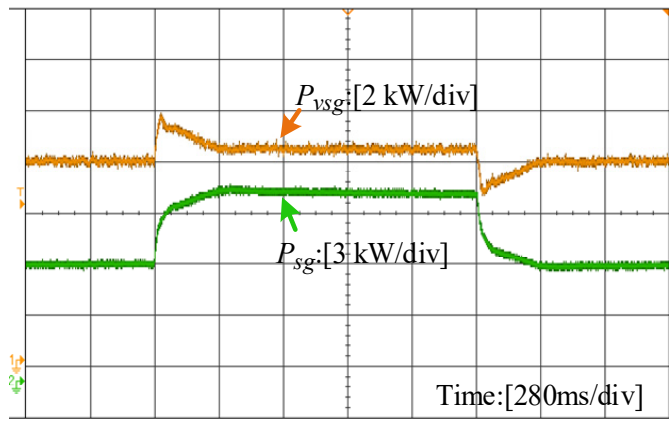

(a)

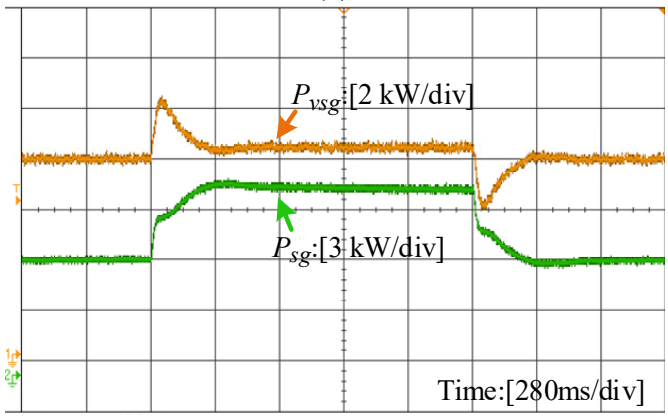

(b)

Figure 19. Cont. 


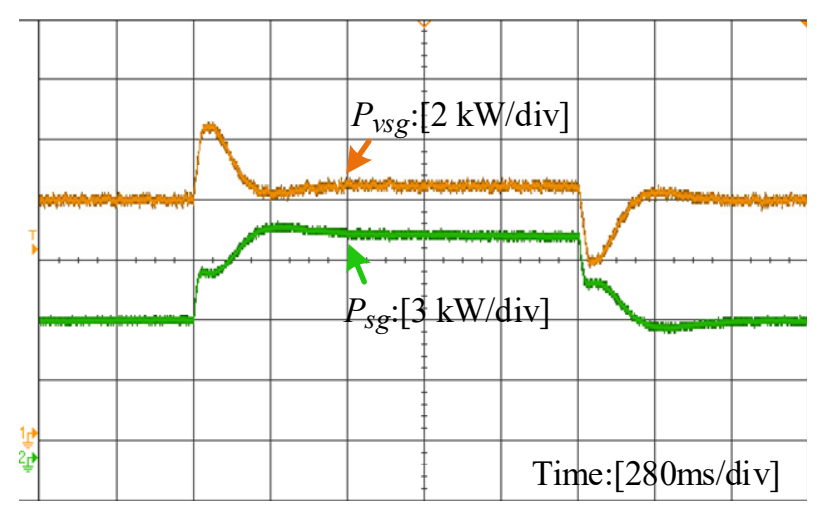

(c)

Figure 19. Output active power waveform: (a) without the high-pass filter; (b) with the high-pass filter; (c) with the high-pass filter (parameters optimized).

\section{Conclusions}

For breaking the limitation of the virtual synchronous generator to support the grid frequency, an active grid frequency support strategy for the VSG-SG coupling system is proposed in this paper. In this method, a high-pass filter is applied to extract the load disturbance component, which is superimposed to the active power loop of the VSG, and then the extra power support for SG can be provided. The effectiveness of the proposed method is verified by the simulations in MATLAB/SIMULINK and HIL experimental tests. Compared to the traditional VSG, the grid-connected inverter with the proposed method can provide additional active power support, which alleviates the power imbalance of SG greatly, and the proposed method thereby presents a better frequency regulation performance under the disturbance. The frequency deviation and the slope of grid frequency are both decreased with the active grid frequency support strategy. Meanwhile, the $H_{\infty}$ and $H_{2}$ norms are used to quantitatively describe the impact of the proposed method on the frequency response. Combined with the particle swarm optimization algorithm, the optimal parameters of the high-pass filter are obtained, and the performance of the proposed active grid frequency support strategy is further improved.

Author Contributions: Conceptualization, L.Y. and J.M.; methodology, J.M.; software, L.Y.; validation, L.Y., J.M., and S.W.; formal analysis, J.M.; investigation, J.M.; resources, S.W.; data curation, L.Y.; writing—original draft preparation, L.Y.; writing—review and editing, J.M.; visualization, S.W.; supervision, T.L., Z.W., R.W., and L.T.; project administration, J.M.; funding acquisition, J.M. and S.W. All authors have read and agreed to the published version of the manuscript.

Funding: This work was supported by the Science and Technology Project of State Grid Corporation of China under grant SGTYHT/19-JS-215.

Conflicts of Interest: The authors declare no conflict of interest.

\section{Appendix A}

The coefficients $a_{0}{ }^{\prime}-a_{4}{ }^{\prime}, b_{0}{ }^{\prime}-b_{3}{ }^{\prime}$ are expressed by the following equations

$$
\begin{aligned}
a_{4}^{\prime} & =J_{1} K_{1} S_{\text {base }} T_{2} T_{j} \omega_{n}+J_{1} K_{2} S_{\text {base }} T_{2} T_{j} \omega_{n} \\
a_{3}^{\prime} & =S_{\text {base }} T_{2} T_{j} k_{p 1}\left(K_{1}+K_{2}\right)+J_{1} S_{\text {base }} T_{j} \omega_{n}\left(K_{1}+K_{2}\right)+D_{1} S_{\text {base }} T_{2} T_{j} \omega_{n}\left(K_{1}+K_{2}\right) \\
a_{2}^{\prime} & =S_{\text {base }} T_{j} k_{p 1}\left(K_{1}+K_{2}\right)+D_{1} S_{\text {base }} T_{j} \omega_{n}\left(K_{1}+K_{2}\right)+J_{1} S_{\text {base }} k_{p 2} \omega_{n}\left(K_{1}+K_{2}\right) \\
& +J_{1} K_{1} K_{2} T \omega_{n}^{2}+K_{1} K_{2} S_{\text {base }} T_{2} T_{j} \\
a_{1}^{\prime} & =J_{1} K_{1} K_{2} \omega_{n}^{2}+K_{1} K_{2} S_{\text {base }} T_{j}+K_{1} S_{\text {base }} k_{p 1} k_{p 2}+K_{2} S_{\text {base }} k_{p 1} k_{p 2} \\
& +D_{1} S_{\text {base }} k_{p 2} \omega_{n}\left(K_{1}+K_{2}\right)+K_{1} K_{2} T k_{p 1} \omega_{n}+D_{1} K_{1} K_{2} T_{2} \omega_{n}^{2} \\
a_{0}^{\prime} & =D_{1} K_{1} K_{2} \omega_{n}^{2}+K_{1} K_{2} k_{p 1} \omega_{n}+K_{1} K_{2} S_{\text {base }} k_{p 2}
\end{aligned}
$$




$$
\begin{aligned}
& b_{3}^{\prime}=-J_{1} K_{2} T_{2} \omega_{n}^{2} \\
& b_{2}^{\prime}=-J_{1} K_{2} \omega_{n}^{2}-D_{1} K_{2} T_{2} \omega_{n}^{2}-K_{2} T_{2} k_{p 1} \omega_{n} \\
& b_{1}^{\prime}=-K_{2} k_{p 1} \omega_{n}-D_{1} K_{2} \omega_{n}^{2}-K_{1} K_{2} T_{2} \omega_{n} \\
& b_{0}^{\prime}=-K_{1} K_{2} \omega_{n}
\end{aligned}
$$

where $K_{1}=\frac{3 E_{1} V_{p c c}}{X_{1}} \cos \delta_{1}, K_{2}=\frac{3 E_{2} V_{p c c}}{X_{2}} \cos \delta_{2}$

The coefficients $a_{0}-a_{4}, b_{0}-b_{3}$ are expressed by the following equations

$$
\begin{aligned}
& a_{5}=J_{1} K S_{\text {base }} T T_{2} T_{j} \omega_{n}\left(K_{1}+K_{2}\right) \\
& a_{4}=K S_{\text {base }} T T_{2} T_{j} k_{p 1}\left(K_{1}+K_{2}\right)+J_{1} K S_{\text {base }} T T_{j} \omega_{n}\left(K_{1}+K_{2}\right) \\
& +J_{1} K S_{\text {base }} T_{2} T_{j} \omega_{n}\left(K_{1}+K_{2}\right)+D_{1} K S_{\text {base }} T T_{2} T_{j} \omega_{n}\left(K_{1}+K_{2}\right)-J_{1} K_{1} K_{2} S_{\text {base }} T T_{2} T_{j} \omega_{n} \\
& a_{3}=K S_{\text {base }} T T_{j} k_{p 1}\left(K_{1}+K_{2}\right)+K S_{\text {base }} T_{2} T_{j} k_{p 1}\left(K_{1}+K_{2}\right)+J_{1} K K_{1} K_{2} T T_{2} \omega_{n}^{2} \\
& +J_{1} K S_{\text {base }} T_{j} \omega_{n}\left(K_{1}+K_{2}\right)+K K_{1} K_{2} S_{\text {base }} T T_{2} T_{j}+D_{1} K S_{\text {base }} T T_{j} \omega_{n}\left(K_{1}+K_{2}\right) \\
& +D_{1} K S_{\text {base }} T_{2} T_{j} \omega_{n}\left(K_{1}+K_{2}\right)+J_{1} K S_{\text {base }} T k_{p 2} \omega_{n}\left(K_{1}+K_{2}\right) \\
& -J_{1} K_{1} K_{2} S_{\text {base }} T T_{j} \omega_{n}-D_{1} K_{1} K_{2} S_{\text {base }} T T_{2} T_{j} \omega_{n} \\
& a_{2}=K S_{\text {base }} T_{j} k_{p 1}\left(K_{1}+K_{2}\right)+D_{1} K S_{\text {base }} T_{j} \omega_{n}\left(K_{1}+K_{2}\right)+K K_{1} K_{2} T T_{2} k_{p 1} \omega_{n} \\
& +K S_{\text {base }} T k_{p 1} k_{p 2}\left(K_{1}+K_{2}\right)+J_{1} K S_{\text {base }} k_{p 2} \omega_{n}\left(K_{1}+K_{2}\right)+D_{1} K K_{1} K_{2} T T_{2} \omega_{n}^{2} \\
& +J_{1} K K_{1} K_{2} \omega_{n}^{2}\left(T+T_{2}\right)+K K_{1} K_{2} S_{\text {base }} T_{j}\left(T+T_{2}\right)-D_{1} K_{1} K_{2} S_{\text {base }} T T_{j} \omega_{n} \\
& D_{1} K S_{\text {base }} T k_{p 2} \omega_{n}\left(K_{1}+K_{2}\right)-J_{1} K_{1} K_{2} S_{\text {base }} T k_{p 2} \omega_{n} \\
& a_{1}=K S_{\text {base }} k_{p 1} k_{p 2}\left(K_{1}+K_{2}\right)+J_{1} K K_{1} K_{2} \omega_{n}^{2}+K K_{1} K_{2} S_{\text {base }} T_{j} \\
& +K K_{1} K_{2} S_{\text {base }} T k_{p 2}+D_{1} K S_{\text {base }} k_{p 2} \omega_{n}\left(K_{1}+K_{2}\right)+K K_{1} K_{2} k_{p 1} \omega_{n}\left(T+T_{2}\right) \\
& +D_{1} K K_{1} K_{2} \omega_{n}^{2}\left(T+T_{2}\right)-D_{1} K_{1} K_{2} S_{\text {base }} T k_{p 2} \omega_{n} \\
& a_{0}=D_{1} K K_{1} K_{2} \omega_{n}^{2}+K K_{1} K_{2} k_{p 1} \omega_{n}+K K_{1} K_{2} S_{\text {base }} k_{p 2} \\
& b_{4}=-J_{1} K K_{2} T T_{2} \omega_{n}^{2} \\
& b_{3}=J_{1} K_{1} K_{2} T T_{2} \omega_{n}{ }^{2}-J_{1} K K_{2} \omega_{n}^{2}\left(T_{2}+T\right)-K K_{2} T T_{2} k_{p 1} \omega_{n}-D_{1} K K_{2} T T_{2} \omega_{n}^{2} \\
& b_{2}=J_{1} K_{1} K_{2} T \omega_{n}^{2}-K K_{2} k_{p 1} \omega_{n}\left(T_{2}+T\right)-D_{1} K K_{2} \omega_{n}^{2}\left(T_{2}+T\right) \\
& -K K_{1} K_{2} T T_{2} \omega_{n}-J_{1} K K_{2} \omega_{n}^{2}+D_{1} K_{1} K_{2} T T_{2} \omega_{n}^{2} \\
& b_{1}=D_{1} K_{1} K_{2} T \omega_{n}^{2}-K K_{2} k_{p 1} \omega_{n}-K K_{1} K_{2} \omega_{n}\left(T_{2}+T\right)-D_{1} K K_{2} \omega_{n}^{2} \\
& b_{0}=-K K_{1} K_{2} \omega_{n}
\end{aligned}
$$

\section{References}

1. Fu, X.; Sun, J.; Huang, M.; Tian, Z.; Yan, H.; Iu, H.H.; Hu, P.; Zha, X. Large-Signal Stability of Grid-Forming and Grid-Following Controls in Voltage Source Converter: A Comparative Study. IEEE Trans. Power Electron. 2021, 36, 7832-7840. [CrossRef]

2. Blaabjerg, F.; Teodorescu, R.; Liserre, M.; Timbus, A.V. Overview of Control and Grid Synchronization for Distributed Power Generation Systems. IEEE Trans. Power Electron. 2006, 53, 1398-1409. [CrossRef]

3. Rocabert, J.; Luna, A.; Blaabjerg, F.; Rodríguez, P. Control of Power Converters in AC Microgrids. IEEE Trans. Power Electron. 2012, 27, 4734-4749. [CrossRef]

4. Hernández, J.C. Grid-Connected Renewable Energy Sources. Electronics 2021, 10, 588. [CrossRef]

5. Bose, B.K. Global Energy Scenario and Impact of Power Electronics in 21st Century. IEEE Trans. Ind. Electron. 2013, 60, $2638-2651$. [CrossRef]

6. Carrasco, J.M.; Franquelo, L.G.; Bialasiewicz, J.T.; Galvan, E.; PortilloGuisado, R.C.; Prats, M.A.M.; Leon, J.I.; Moreno-Alfonso, N. Power-Electronic Systems for the Grid Integration of Renewable Energy Sources: A Survey. IEEE Trans. Ind. Electron. 2006, 53, 1002-1016. [CrossRef]

7. Xiong, L.; Liu, X.; Zhang, D.; Liu, Y. Rapid Power Compensation Based Frequency Response Strategy for Low Inertia Power Systems. IEEE J. Emerg. Sel. Top. Power Electron. 2020, 1. [CrossRef]

8. Hashmi, K.; Mansoor Khan, M.; Jiang, H.; Umair Shahid, M.; Habib, S.; Talib Faiz, M.; Tang, H. A Virtual Micro-Islanding-Based Control Paradigm for Renewable Microgrids. Electronics 2018, 7, 105. [CrossRef]

9. Xiong, L.; Liu, X.; Zhao, C.; Zhuo, F. A Fast and Robust Real-Time Detection Algorithm of Decaying DC Transient and Harmonic Components in Three-Phase Systems. IEEE Trans. Power Electron. 2020, 35, 3332-3336. [CrossRef]

10. Ustun, T.S.; Aoto, Y. Analysis of Smart Inverter's Impact on the Distribution Network Operation. IEEE Access 2019, 7, 9790-9804. [CrossRef] 
11. Ustun, T.S.; Aoto, Y. Impact of Power Conditioning Systems with Advanced Inverter Capabilities on the Distribution Network. In Proceedings of the 2018 53rd International Universities Power Engineering Conference (UPEC), Glasgow, UK, 4-7 September 2018.

12. Xue, Y.; Guerrero, J.M. Smart Inverters for utility and Industry Applications. In Proceedings of the PCIM Europe 2015, International Exhibition and Conference for Power Electronics, Intelligent Motion, Renewable Energy and Energy Management, Nuremberg, Germany, 19-20 May 2015.

13. Beck, H.-P.; Hesse, R. Virtual Synchronous Machine. In Proceedings of the 9th International Conference on Electrical Power Quality and Utilisation, Barcelona, Spain, 9-11 October 2007.

14. Driesen, J.; Visscher, K. Virtual Synchronous Generators. In Proceedings of the 2008 IEEE Power and Energy Society General Meeting-Conversion and Delivery of Electrical Energy in the 21st Century, Pittsburgh, PA, USA, 20-24 July 2008.

15. Zhong, Q.-C.; Weiss, G. Synchronverters: Inverters That Mimic Synchronous Generators. IEEE Trans. Ind. Electron. 2011, 58, 1259-1267. [CrossRef]

16. Chen, Y.; Hesse, R.; Turschner, D.; Beck, H.-P. Improving the Grid Power Quality Using Virtual Synchronous Machines. In Proceedings of the 2011 International Conference on Power Engineering, Energy and Electrical Drives, Malaga, Spain, 11-13 May 2011.

17. Yan, X.; Rasool, A.; Abbas, F.; Rasool, H.; Guo, H. Analysis and Optimization of the Coordinated Multi-VSG Sources. Electronics 2019, 8, 28. [CrossRef]

18. Soni, N.; Doolla, S.; Chandorkar, M.C. Improvement of Transient Response in Microgrids Using Virtual Inertia. IEEE Trans. Power Deliv. 2013, 28, 1830-1838. [CrossRef]

19. Shintai, T.; Miura, Y.; Ise, T. Oscillation Damping of a Distributed Generator Using a Virtual Synchronous Generator. IEEE Trans. Power Deliv. 2014, 29, 668-676. [CrossRef]

20. Wu, H.; Ruan, X.; Yang, D.; Chen, X.; Zhao, W.; Lv, Z.; Zhong, Q.-C. Small-Signal Modeling and Parameters Design for Virtual Synchronous Generators. IEEE Trans. Ind. Electron. 2016, 63, 4292-4303. [CrossRef]

21. Fang, J.; Li, H.; Tang, Y.; Blaabjerg, F. On the Inertia of Future More-Electronics Power Systems. IEEE J. Emerg. Sel. Top. Power Electron. 2019, 7, 2130-2146. [CrossRef]

22. Alipoor, J.; Miura, Y.; Ise, T. Power System Stabilization Using Virtual Synchronous Generator with Alternating Moment of Inertia. IEEE J. Emerg. Sel. Top. Power Electron. 2015, 3, 451-458. [CrossRef]

23. Wang, F.; Zhang, L.; Feng, X.; Guo, H. An Adaptive Control Strategy for Virtual Synchronous Generator. IEEE Trans. Ind. Appl. 2018, 54, 5124-5133. [CrossRef]

24. Li, J.; Wen, B.; Wang, H. Adaptive Virtual Inertia Control Strategy of VSG for Micro-Grid Based on Improved Bang-Bang Control Strategy. IEEE Access 2019, 7, 39509-39514. [CrossRef]

25. Hou, X.; Sun, Y.; Zhang, X.; Lu, J.; Wang, P.; Guerrero, J.M. Improvement of Frequency Regulation in VSG-Based AC Microgrid Via Adaptive Virtual Inertia. IEEE Trans. Power Electron. 2020, 35, 1589-1602. [CrossRef]

26. Du, Y.; Guerrero, J.M.; Chang, L.; Su, J.; Mao, M. Modeling, Analysis, and Design of a Frequency-Droop-Based Virtual Synchronous Generator for Microgrid Applications. In Proceedings of the 2013 IEEE ECCE Asia Downunder, Melbourne, VIC, Australia, 3-6 June 2013.

27. Yu, B. An Improved Frequency Measurement Method from the Digital PLL Structure for Single-Phase Grid-Connected PV Applications. Electronics 2018, 7, 150. [CrossRef]

28. Fang, J.; Li, H.; Tang, Y.; Blaabjerg, F. Distributed Power System Virtual Inertia Implemented by Grid-Connected Power Converters. IEEE Trans. Power Electron. 2018, 33, 8488-8499. [CrossRef]

29. Liu, J.; Miura, Y.; Ise, T. Comparison of Dynamic Characteristics between Virtual Synchronous Generator and Droop Control in Inverter-Based Distributed Generators. IEEE Trans. Power Electron. 2016, 31, 3600-3611. [CrossRef]

30. Liu, J.; Miura, Y.; Bevrani, H.; Ise, T. Enhanced Virtual Synchronous Generator Control for Parallel Inverters in Microgrids. IEEE Trans. Smart Grid 2017, 8, 2268-2277. [CrossRef]

31. Shi, K.; Song, W.; Ge, H.; Xu, P.; Yang, Y.; Blaabjerg, F. Transient Analysis of Microgrids with Parallel Synchronous Generators and Virtual Synchronous Generators. IEEE Trans. Energy Convers. 2020, 35, 95-105. [CrossRef]

32. Paquette, A.D.; Reno, M.J.; Harley, R.G.; Divan, D.M. Transient Load Sharing Between Inverters and Synchronous Generators in Islanded Microgrids. In Proceedings of the 2012 IEEE Energy Conversion Congress and Exposition (ECCE), Raleigh, NC, USA, 15-20 September 2012.

33. Cheng, H.; Shuai, Z.; Shen, C.; Liu, X.; Li, Z.; Shen, Z.J. Transient Angle Stability of Paralleled Synchronous and Virtual Synchronous Generators in Islanded Microgrids. IEEE Trans. Power Electron. 2020, 35, 8751-8765. [CrossRef]

34. Huang, L.; Xin, H.; Dorfler, F. Ho-Control of Grid-Connected Converters: Design, Objectives and Decentralized Stability Certificates. IEEE Trans. Smart Grid 2020, 11, 3805-3816. [CrossRef]

35. Doyle, J.C.; Glover, K.; Khargonekar, P.P.; Francis, B.A. State Space Solutions to Standard H2 and Ho Control Problems. IEEE Trans. Autom. Control. 1989, 34, 831-847. [CrossRef]

36. Latif, A.; Hussain, S.M.S.; Das, D.C.; Ustun, T.S. Optimum Synthesis of a BOA Optimized Novel Dual-Stage PI - (1 + ID) Controller for Frequency Response of a Microgrid. Energies 2020, 13, 3446. [CrossRef]

37. Das, D.C.; Roy, A.K.; Sinha, N. GA Based Frequency Controller for Solar Thermal-diesel-wind Hybrid Energy Generation/Energy Storage System. Int. J. Electr. Power Energy Syst. 2012, 43, 262-279. [CrossRef] 
38. Latif, A.; Hussain, S.M.S.; Das, D.C.; Ustun, T.S. State-of-the-art of Controllers and Soft Computing Techniques for Regulated Load Frequency Management of Single/Multi-area Traditional and Renewable Energy based Power Systems. Appl. Energy 2020, 266, 114858. [CrossRef]

39. Del Valle, Y.; Venayagamoorthy, G.K.; Mohagheghi, S.; Hernandez, J.C.; Harley, R.G. Particle Swarm Optimization: Basic Concepts, Variants and Applications in Power Systems. IEEE Trans. Evol. Comput. 2008, 12, 171-195. [CrossRef]

40. Seo, J.; Im, C.; Heo, C.; Kim, J.; Jung, H.; Lee, C. Multimodal Function Optimization Based on Particle Swarm Optimization. IEEE Trans. Magn. 2006, 42, 1095-1098. [CrossRef] 